\title{
Presentación
}

\section{Antigitanismo en Europa: conceptualización, historia reciente y aportes al conocimiento de una forma específica de racismo}

\author{
Manuel Ángel Río-Ruiz y Carolina García-Sanz (coordinadores) \\ Universidad de Sevilla
}

Hay distintas maneras de confinar a un pueblo en el lado oscuro de la democracia. El rechazo y la postergación histórica de la población Romá1 en Europa pueden explicarse de distintas maneras. La desatención institucional y la desatención académica son solo dos de los factores que han contribuido a la reproducción histórica de la exclusión, continuamente actualizada, de aproximadamente doce millones de europeos.

\footnotetext{
${ }^{1}$ Como se recoge en los distintos documentos de trabajo para la integración de la comunidad romaní en la Unión Europea (http://ec.europa.eu/justice/discrimination/roma/index en.htm), términos como Roma (sustantivo)/ romaní (adjetivo) aluden a distintos colectivos y personas, con importantes diferencias lingüísticas y culturales ligadas a diferentes espacios de movilidad geográfica y a sus tradiciones particulares a nivel nacional y/o estatal. De hecho, estos grupos etiquetados suelen reconocerse en otro tipo de filiaciones más específicas (Travellers, Manouches, Ashkali, Sinti, Boyash, Gitanos) variando en función del contexto nacional. Pese a la estereotipia negativa generada en torno al uso público del término gitano en otros países y a la recomendación de su sustitución por el de romaní, en artículos donde se dirige la atención al propio contexto español o éste es el de referencia para sus autores, optamos por su uso ya que la propia comunidad romaní española lo usa -en un sentido positivo- para distinguirse de la sociedad mayoritaria. "Gitano" entrecomillado se usará para referir el estereotipo negativo generado en el proceso de creación de alteridad por las sociedades mayoritarias.
} 
Lo apuntaba hace quince años el líder social romá Valeriu Nicolae (2006), a quien debemos la más utilizada definición de anti-gitanismo. El anti-gitanismo es una de las ideologías justificadoras de la discriminación y reproductoras del odio más tardíamente atendidas, más violentas, y que con menor grado de censura estructural y edulcoración se manifiesta, incluso, en el discurso público de líderes sociales y políticos y de los medios de comunicación. De hecho, a pesar de que encaja en las descripciones académicas del racismo, hasta hace muy poco la academia ha ignorado o simplemente prestado una atención superficial a la difícil situación de los gitanos y gitanas, y no ha hecho apenas esfuerzo para teorizar o analizar la situación que sufren.

En la última década, no obstante, se han producido avances como producto también de la investigación de miembros de las comunidades romaníes, en buena medida inspirados por intelectuales como Ian Hancock (2002). Hay obras colectivas que nos aproximan a la historia reciente y diferentes facetas del antigitanismo en distintos países de Europa del Este (Kyuchukov et al, 2012). También en la última década bajo un contexto internacional en el que, como señalan algunos autores, la gitanofobia resiste como "última forma aceptable de racismo europeo" (McGarry 2017) han aparecido publicaciones centradas en la discriminación legal e institucional de los romá. En este marco destacamos, por un lado, el número coordinado por Marinaro y Sigona (2011), dedicado a analizar las consecuencias de las políticas de exclusión de los romá Italia y, por otro, un dossier publicado en España recientemente estudiando las representaciones sociales de los romaníes a lo largo de la historia (Sierra 2019).

A buen seguro este nuevo monográfico sobre nuestro poco mirado problema con los gitanos y las gitanas reúne limitaciones y reproduce ausencias; pero representa el esfuerzo de un grupo de académicas/os, y de un valioso proyecto editorial, para que la llamada "cuestión gitana" sea de una vez "incluida" e "integrada" en el lugar que le corresponde: el del amplio espacio social que sigue recorriendo a sus anchas el anti-gitanismo en Europa.

Sin embargo, hasta la tardía fecha de 2005 la UE no incorporó a su léxico el término "anti-gitanismo". Hasta entonces no definió institucionalmente esta forma específica de ideología y de discriminación racista focalizada en comunidades de europeos que, a cambio, venían de sufrir una sistemática persecución y un amplio exterminio bajo el dominio del III Reich, entre otros intentos estatales previos de limpieza étnica a menor escala, como el que se remonta a la "Gran Redada" española de 1749. Desde ese año 2005 diversos organismos y actores conceptualizan el fenómeno con pocas discrepancias. Estas 
estarían ligadas más al énfasis en ciertos aspectos del fenómeno² que a las ausencias en las definiciones de otros elementos que lo constituyan (Nicolae 2006; ECRI 2011; Kyuchukov 2012; Agafin 2015; Cortés y End 2019).

$\mathrm{El}$ anti-gitanismo se define como una ideología esencialista y homogeneizadora que da lugar a una forma de racismo particularmente persistente, violenta, recurrente, banalizada, que deshumaniza a las víctimas y que explota el discurso del odio y del miedo. Esta forma específica de racismo se sigue manifestando extensamente bajo distintas prácticas de estigmatización y discriminación, todas flagrantes y generadoras de desventajas sociales estructurales y situaciones de amplia exclusión. Situaciones que se reproducen generación tras generación erosionando al cabo la propia percepción de las personas que sufren este racismo.

El anti-gitanismo representaría por tanto un hecho social total que integra a la hora de manifestarse en diferentes niveles de articulación sociopolítica la totalidad de elementos o ingredientes del racismo (Wieviorka 1992).

En primer lugar, y como ideología que atribuye significado a los hechos sociales mediante una representación social homogeneizadora, deformada y esencialista del otro grupo, el anti-gitanismo se sustenta sobre la base del prejuicio étnico. Éste se compone a su vez de emociones, creencias y actitudes hostiles. Son tres duras y extendidas materias primas conformadas bajo el peso de la historia y bajo el peso de la ideología culturalmente dominante que se va acumulando sobre los miembros de una sociedad. En cada momento societal esta ideología, reconocida bajo el implícito de jerarquías entre categorías de grupos humanos, es reproducida al servicio de la preservación de barreras intergrupales. Se vale para ello de diferentes mecanismos de transmisión cultural, desde la socialización de la infancia hasta la literatura o los medios de comunicación.

El discurso público juega en todo momento un papel fundamental. Los medios de comunicación (y las redes sociales) rara vez sirven para erradicar prejuicios si ellos están muy asentados entre las audiencias, como ocurre especialmente con la población gitana. En cambio, medios de comunicación y redes sociales son agencias fundamentales en consolidar y legitimar la expresión pública de los estereotipos existentes, así como a la hora de la banalizar y expandir nuevos

2 Como el carácter particularmente deshumanizador del "otro" que revela el antigitanismo y la recurrente biologización de la diferencia que siguen sufriendo los romá en un contexto, en cambio, de dominio del llamado "racismo diferencialista" (Rorke 1999, cit. Nicolae 2006). 
imaginarios de credulidad que alimentarán los estereotipos, barreras, antagonismos y malas ideas intergrupales existentes.

Los prejuicios circulan por canales informales e institucionalizados de sociabilidad como rebrotados virus entre rebaños que nunca se inmunizan y que devoran la diversidad entre los miembros de cualquier comunidad. Tras ello devuelven a la sociedad mayoritaria a "los otros" bajo imágenes de desviación moral y riesgo social donde, como sugiere la literatura del narcisismo de las diferencias menores, las mayorías sociales proyectan sus miedos y ansiedades.

Aunque no hay correspondencia ipso facto entre creencias, actitudes y acciones de discriminación, los prejuicios son la base de las situaciones y prácticas de discriminación, otro de los elementos fundamentales del racismo y del antigitanismo. La discriminación supone una acción de desigualdad de trato en función de una categorización que actúa como elemento de diferenciación no neutro, ya que reporta desventajas a los individuos que se ven categorizados en distintas situaciones a la hora de frecuentar espacios sociales, obtener empleo, educación, vivienda, o acceder a distintos servicios.

La discriminación étnica tiende a reproducirse en las relaciones interpersonales a través de la minimización de relaciones, contratos, contactos e interdependencias. No obstante, en algún momento, detrás de estas situaciones bajo la vida cotidiana, nos encontramos con la discriminación institucional con un doble efecto. Fuente en sí misma de desigualdad de trato, la discriminación institucional naturaliza la jerarquización y la discriminación interpersonal. En el caso del anti-gitanismo conviene subrayar el arraigo profundo de las prácticas, medidas y políticas públicas de discriminación institucional.

La misma puede reproducirse sin amparo legal, incluso sin conciencia o intención de explícita discriminar. En el caso de los gitanos la discriminación oficial se materializa en distintos contextos. La lista de escenarios sería demasiado larga. Por un lado, en la segregación escolar y en la infrarrepresentación de gitanas y gitanos en muchos ámbitos de la sociedad, como la universidad o la política. Algunas y algunos de los pocos que llegan a estos sitios lo hacen bajo tal cúmulo de precios y de certificados provisionales de admisión, de dificultades, $\mathrm{y}$ de precauciones que nunca terminan, que optan por invisibilizarse antes de exponerse a quedar resignificados y re-visibilizados en los nuevos espacios conseguidos, en vez de como individuos, como meras excepciones o confirmaciones de lo que otros atribuyen estereotípicamente a la grupalidad a la que se les reduce. 
Por otro lado, la discriminación institucional se materializa especialmente en situaciones de desigualdad de trato oficial en función de marcas étnicas ante situaciones análogas. Eso es lo que demuestran continuamente las asimetrías y los distintos filtros sociales que, especialmente de si de gitanos hablamos, aplican las instituciones encargadas de vigilar a los padres para vigilar derechos de la infancia, así como los cuerpos funcionariales especialmente dedicados a la prevención, persecución y castigo de los delitos menos blanqueados.

La discriminación sistemática configura otro elemento del racismo y del antigitanismo: la segregación: la separación y minimización de interdependencias entre ciertos grupos ubicados en diferentes espacios, regulados bajo reglas sociales aparentemente diferenciadas. La segregación de la población gitana es un fenómeno complejo, se nos dice muchas veces como preludio de simplificaciones. Sin embargo, aunque no quepan lecturas unicausales del fenómeno, sin atender al peso del anti-gitanismo no cabe explicación posible de la segregación gitana, tantas veces evaluada mediante simplificaciones. Mediante atajos culturalistas que obvian el efecto de la exclusión histórica continuada por parte de las mayorías culturalmente dominantes en los límites que se autoimponen las minorías racializadas, como los gitanos, para resistir: para protegerse frente al odio, la desigualdad de trato e incluso la violencia repetidamente confirmada desde las propias filas de quienes a lo largo de la historia han comenzado gritando "por qué no se integran" ciertas minorías.

La violencia sería el núcleo duro del racismo. En el caso de los gitanos la violencia racista se ha manifestado y continúa en Europa manifestándose a todos los niveles, esto es, bajo distintos grados de articulación social y política, desde el hostigamiento en redes sociales a la persecución organizada. Son demasiados los casos como para no pensar que los llamados Estados de Derecho se ven frecuentemente suspendidos si de gitanos hablamos. Las sociedades occidentales han individualizado sus respuestas ante el delito. En cambio, como muestran los pogromos y episodios de violencia civil registrados bajo pautas similares en España y toda Europa, los delitos cometidos por algún miembro de la comunidad gitana, en lugar de individualizarse como ocurriría si un ciudadano británico blanco asesinara niñas en la Costa del Sol, suelen desatar respuestas comunitarias represivas siguiendo líneas étnicas. Esto sucede sobre todo allí donde las mayorías más implicadas han podido contar con la implicación de autoridades o la desaplicación de funcionarios en la salvaguarda del orden público en situaciones que, se sabe, son preludio de festivales de violencia etnicista. 
Hay quienes distinguen entre niveles del racismo en función de su grado de articulación societal y de su penetración institucional (Wieviorka 1992). Poco afortunada en general, esta distinción entre racismo infrapolítico y racismo articulado políticamente no sirve ni remotamente si de pueblos romaníes hablamos. Ni ahora ni antes. El antigitanismo ha constituido históricamente un fenómeno articulado políticamente. Como ya se ha apuntado, ha resistido históricamente los embates de la condena pública al racismo como ideología de Estado, descansando sobre un conjunto de representaciones e imágenes estigmatizantes reproducidos pertinazmente sobre discursos político-legales, científicos, eruditos, literarios y artísticos cuya vigencia no deja de causar sonrojo en Europa. "Raza" y "etnia" constituyen conceptos históricos cambiantes, resultando relevante historiográficamente conocer los procesos de racialización o etnicización. En este sentido, la academia ha demostrado muy escaso interés por indagar en los mecanismos a través de los cuales una sociedad define, etiqueta y trata a la población romaní, así como por estudiar la capacidad de respuesta en las propias comunidades.

Resultaría poco discutible que la percepción de los gitanos como un grupo de población distinta en Europa nace de un arquetipo referencial negativo, que permearía la mentalidad pública desde la Edad Moderna. La esencialización, por parte de la sociedad mayoritaria, de un colectivo a partir de un estilo de vida itinerante, identificado como potencialmente delictivo, les convertiría en objetivo especializado de una acción pública represiva, cuyo fundamento legal con sus dispositivos administrativos y disciplinarios se desarrollaron en sorprendente sincronía. El afán racionalizador del Estado-Nación tendió claramente a la eliminación de la figura del "gitano", identificado con aquel que se mantenía voluntariamente alejado de la "norma": insumiso frente a las reglas que acotaban las relaciones familiares, sociales y económicas y definían las experiencias modélicas del ciudadano "activo". De ese modo, la "cuestión gitana", muy especialmente sobre la base de la movilidad, quedaría problematizada por el Estado demo-liberal (Lucassen, Willems y Cottar 1998). La figura del "nómada" o "gitano" terminaba confundiéndose con la del "vagabundo" o "sospechoso".

En Francia, por ejemplo, podríamos citar las sucesivas leyes de vigilancia sobre los "Bohémiens" (About 2010); en Gran Bretaña las Vagrancy Acts o las Hawkers and Pedlars Acts (Mayall 1995). Un caso particular, en el contexto demo-liberal, podría ser el de Italia, que tal como ha señalado una de las especialistas que contribuyen a este dossier, sitúa a los gitanos en una especie de estado de excepción dentro del Estado de derecho en los años inmediatamente precedentes a la Primera Guerra Mundial (Illuzi 2014). De hecho, conforme 
avanzó el siglo XIX, la criminalización del "gitano" terminaría impregnando reglamentos -por una vía u otra- de excepción en la mayoría de los regímenes liberales. Como resultado de ese proceso, por ejemplo, en 1912 se introduciría el famoso carnet antropométrico en Francia con aplicación preferente sobre este grupo de población, un método que sería muy bien acogido por la mayor parte de los cuerpos policiales europeos en vísperas de la Primera Guerra Mundial. De hecho, el control de la movilidad transfronteriza de este colectivo sería una preocupación fundamental en los cuerpos de seguridad francesa, presente en la década siguiente e incorporada por la International Criminal Police Commission (ICPC o Interpol).

De ese modo, a principios del siglo $\mathrm{XX}$, asistimos a una vuelta de tuerca en la discriminación legal del gitano conectada con el éxito de las tesis biologicistas y profilácticas, y su impacto en el Derecho Penal a partir de la idea patológica del anti-social desarrollada ampliamente en Italia y Alemania, con gran influencia por ejemplo en España. Este nuevo clima se traduciría en la época de entreguerras en la pseudo-racialización del "gitano", aún resistente o refractario a las leyes y, por tanto, en un endurecimiento de su tratamiento público. En algunos casos como el del régimen nazi, comportaría la trágica disolución de las fronteras entre la "domesticación" pública y su exterminio físico. Tras la Segunda Guerra Mundial y la desautorización del racismo como ideología pública en la Europa democrática, en la Europa el Este continuaría la asimilación coactiva de aquéllos cuyos estilos de vida se consideraban incompatibles con las expectativas comunistas. La conversión de los gitanos, por un lado, en camaradas productivos a través de políticas forzosas de asentamiento e internamiento en campos de trabajo y, por otro, el reconocimiento ambiguo de su condición como nacionales en los respectivos ordenamientos constitucionales de Checoslovaquia, Bulgaria, Hungría y Rumanía terminaría consolidándolos como minorías más numerosas en dichos países. Pero la discriminación institucional no sólo persistía a uno de los lados del telón de acero. El Consejo de Europa en 1967 recomendaba a su Sección de Asuntos Sociales que abordara dicha cuestión, con especial atención a lo que estaba ocurriendo en países occidentales. En este sentido, la regulación del ejercicio de actividades ambulantes y del régimen administrativo y no penal aplicable a las personas sin domicilio fijo continuó en la forma mentis de los legisladores del "mundo libre". La ley francesa de 3 de enero 1969 estipulaba que los carnets de circulación de determinados nómadas debían ser visados por la policía con mayor frecuencia que otros. En este mismo apartado, podría considerarse la legislación holandesa (llamada «ley de carromatos») de 1968 o los efectos negativos de la Caravan Sites Act británica del mismo año. 
Como muestra este monográfico los poderes públicos han sido decisivos en la reproducción obstinada de imaginarios racistas y en la preservación de jerarquías y límites que no han hecho si no achicar las oportunidades vitales y los derechos de los romaníes europeos, así como destruir oportunidades de convivencia intercultural. Desde un enfoque holístico e interdisciplinar, aunando casos de estudio atentos a las raíces socio-históricas del anti-gitanismo, nuestra propuesta pone el acento, primero, en el carácter transnacional del mismo como expresión de procesos mentales que han demostrado gran capacidad de adaptación a los cambios sociales, políticos y culturales de los últimos cien años. Y segundo, pese a la temática, trata de sortear las trampas esencialistas del "anti-gitanismo" proyectando la imagen de los romaníes como "eternas víctimas" de estructuras sistémicas opresoras. Este monográfico también dirige su mirada hacia la capacidad de agencia de la comunidad gitana, y de su asociacionismo, para articular respuestas y transformar en un sentido positivo la sociedad en su conjunto. Por eso, en el análisis histórico se conjuga la atención a los mecanismos de penalización pública en artículos como el de Jennifer Illuzi sobre Alemania e Italia en la primera mitad del siglo XX o el de Carolina García Sanz sobre la España reciente, con aportaciones como la de María Sierra y su caso de estudio en Francia desde la potencialidad creativa para enfrentarse a las inseguridades colectivas de la Guerra Fría.

Las consecuencias de la discriminación institucional en la segregación residencial de los gitanos españoles bajo el franquismo ocupan a Manuel Río. A esos barrios etnificados traslada posteriormente su análisis Manuel Trujillo. Este último nos ofrece un estudio de la altísima abstención electoral de estos barrios mayormente gitanos. Su trabajo hipotetiza y ofrece datos que apuntan al peso prioritario de la exclusión socioeconómica en el fenómeno de la desafección política de la mayor parte de los gitanos de barrios marginalizados. Fenómeno que corre el riesgo de atribuirse a rasgos culturales sustancializados, lo que ocultaría el peso de la pobreza, también en las proyecciones de cambio social mediante formas convencionales de participación política. Trujillo aplica estrategias para poder trabajar con datos específicos sobre exclusión de la población gitana. Precisamente la calidad de los indicadores europeos para medir y comparar la exclusión gitana, así como el antigitanismo, ocupan a María Luisa Jiménez y Patricia Sánchez, cuyo texto abre el dossier.

Las continuidades entre las formas de racialización y niveles de segregación de los gitanos en diferentes urbes europeas ocupan a Giovani Picker. El autor trata de desvelarnos los paralelismos entre las ideologías y mecanismos de gestión colonial de poblaciones que aplicaron las autoridades europeas, durante la época 
de los Imperios, y las que actualmente aplican otras autoridades hacia comunidades romá. Finalmente, como aportación para la sección texto clásico, el profesor de Derecho Constitucional Fernando Rey nos ofrece un análisis del discurso del Diputado socialista de etnia gitana Ramírez Heredia. Discurso histórico, también reproducido aquí, y que significó la abolición de medidas discriminatorias vigentes hasta 1978 en el orden jurídico español.

En ninguna sociedad europea, tampoco en la española, se da con los gitanos un "racismo infrapolítico" (Wieviorka 1992) mantenido a nivel microsocial y limitado a la circulación de prejuicios, de rumores acusatorios, y de acciones interpersonales de discriminación bajo la vida cotidiana. La deshumanización histórica que ha sufrido este pueblo, algo que ha llevado a la banalización y hasta la justificación de la violencia contra sus integrantes, ha deparado más de un intento de limpieza étnica organizada con toda la maquinaria de distintos Estados. En nuestros días, en gran medida por la instrumentalización política en contextos de crisis del odio preexistente a las minorías, el anti-gitanismo está convirtiéndose en frecuente banderín de enganche de grupos y movimientos sociales crecientemente articulados políticamente para competir por el poder en las instituciones y en las calles. Mientras tanto la Unión europea sigue mirando a Hungría.

\section{BIBLIOGRAFÍA}

ABOUT, I. (2010): "De la libre circulation au contrôle permanent. Les autorités françaises face aux mobilités tsiganes transfrontalières, 1860-1930". Cultures \& Conflits, (76): 15-37.

AGAFIN, T. (2015): When Stereotype Meets Prejudice: Antiziganism in European Societies, Stuttgart: Ed. Ibidem.

CORTES-GOMÉZ, I. y END, M. (2019): "Introduction: Contemporary Dimensions of Antigypsyism in Europe", en Dimensions of Antigypsyism in Europe, editado por CORTÉS GÓMEZ, I. Y END, M., European Network against Racism (ENAR) and the Central Council of German Sinti and Roma, pp. 19-28. Consulta: 20 de mayo de 2019 (https://www.enar-eu.org/BookDimensions-of-Antigypsyism-in-Europe)

EUROPEAN COMMISSION AGAINST RACISM AND INTOLERANCE (ECRI): (2011): "Recomendación de Política General № 13 de la ECRI sobre la lucha contra el antigitanismo y las discriminaciones contra los Romaníes/Gitanos". Consejo Europeo. Estrasburgo. Consulta: 2 de abril de 2019 
(https://rm.coe.int/ecri-general-policy-recommendation-no-13-oncombating-anti-gypsyism-an/16808b5aef)

HANCOCK, I. (2002): We are the Romani People. University of Hertfordshire Press.

ILLUZI, J. (2014): Gypsies in Germany and Italy, 1861-1914. Lives Outside the Law, Basingstoke, Palgrave.

KYUCHUKOV, H. ed. (2012): New faces of antigypsyism in modern Europe. Praga: Disponible en: http://jaroslavbalvin.eu/wpcontent/uploads/2014/10/AG_04.pdf

LUCASSEN L., WILLEMS W., COTTAR A. (1998): Gypsies and Other Itinerant Groups. A Socio-Historical Approach, New York, Macmillan Press.

MAYALL, D. (1995): English Gypsies and State Police, Hatfield, Hertfordshire Press.

MCGARRY, A. (2017): Romaphobia: The Last Acceptable Form of Racism, London, Zed Books.

MARINARO, I. y SIGONA, N. (2011): "Anti-Gypsyism and the politics of exclusion: Roma and Sinti in contemporary Italy". Journal of Modern Italian Studies 16 (5), pp. 583-589

NICOLAE, V. (2006): Towards a definition of anti-gypsyism. Disponible: http://www.ergonetwork.org/media/userfiles/media/egro/Towards\%20a $\% 20$ Definition\%20of\%20Anti-Gypsyism.pdf - Right to Remember A Hand

SIERRA, M. coord. (2019): “Creando subalternos. Imágenes sobre el pueblo gitano". Historia Social, núm. 93.

WIEVIORKA, M. (1992): El espacio del racismo. Barcelona: Paidós. 